\title{
Mental health capacity building in low and middle income countries: the Emerald Programme
}

Received 19 September 2017; Accepted 24 September 2017

Key words: Global mental health, low and middle income countries, capacity building.

This is a time of unprecedented interest in the field of global mental health. Since the WHO World Mental Health Report of 2001 (World Health Organization, 2001) there has been an accelerating tempo of evidence and initiatives. These show an appreciation of the scale of the mental health gap across all of the world (Wang et al. 2007; Thornicroft et al. 2017), and demonstrate the strengthening evidence base of effective interventions to treat people with mental illnesses in low and middle income countries (LMICs) (Patel \& Thornicroft, 2009; Patel et al. 2016; Petersen et al. 2016; World Health Organisation., 2016).

In terms of the inter-related elements necessary to strengthen health systems (including primary care, community care and specialist care) in providing treatment to people with mental illness, one aspect that has been relatively neglected is the need to provide actionable and sustained training to staff (Thornicroft et al. 2012). This edition of Epidemiology and Psychiatric Sciences includes three papers that address this issue. The Editorial by Semrau et al. outlines capacitybuilding approaches and outputs to support mental health system strengthening for three target groups (i) mental health service users and caregivers, (ii) service planners and policy-makers, and (iii) mental health researchers) in six LMICs in Sub-Saharan Africa and in Asia (Ethiopia, India, Nepal, Nigeria, South Africa and Uganda).

The second paper by Hanlon et al. focuses on the methods, which can be used to evaluate the impact of such capacity-building in these three target groups. Third, the paper by Lempp et al. reports on a crosscountry qualitative study of in-depth interviews with service users and caregivers to assess their involvement in mental health system strengthening. This is important because service user involvement in any

* Address for correspondence: G. Thornicroft, Centre for Global Mental Health, King's College London, Institute of Psychiatry, Psychology and Neuroscience, de Crespigny Park, London SE5 8AF, UK.

(Email: graham.thornicroft@kcl.ac.uk) aspect of mental health care planning, provision or evaluation is still in its infancy in many LMICs (Thornicroft \& Tansella, 2005), although in several countries this is now gaining pace (Samudre et al. 2016; Abayneh et al. 2017; Gurung et al. 2017).

These papers arise from the EU-funded Emerald (Emerging mental health systems in low- and middle-income countries) programme, which is investigating mental health system strengthening in these six countries (see www.emerald-project.eu) (Semrau et al. 2015) alongside financial equity (Chisholm et al. 2017), integrated care (Petersen et al. 2017) and establishing mental health system indicators (Jordans et al. 2016; Upadhaya et al. 2016).

An important part of the legacy of Emerald is the development of 27 Masters-level teaching modules, and three short courses on mental health system strengthening (for service users and caregivers; policymakers and planners; and mental health researchers), in addition to having provided support for pre- and post-doctoral research staff, These teaching packages will be made available under a Creative Commons open access license in the near future via the Emerald website at King's College London. The capacitybuilding approaches taken by Emerald may serve as a model to be adapted for other LMICs for future initiatives designed to support knowledge, attitude and skill enhancement for everyone concerned with mental health system strengthening in LMICs.

\section{Acknowledgements}

GT is supported by the National Institute for Health Research (NIHR) Collaboration for Leadership in Applied Health Research and Care South London at King's College London Foundation Trust. The views expressed are those of the author(s) and not necessarily those of the NHS, the NIHR or the Department of Health. GT acknowledges financial support from the Department of Health via the National Institute for Health Research (NIHR) Biomedical Research Centre 
and Dementia Unit awarded to South London and Maudsley NHS Foundation Trust in partnership with King's College London and King's College Hospital NHS Foundation Trust. GT and MS are supported by the European Union Seventh Framework Programme (FP7/2007-2013) Emerald project.

G. Thornicroft ${ }^{*}$ and M. Semrau Centre for Global Mental Health, King's College London, Institute of Psychiatry, Psychology and Neuroscience, de

Crespigny Park, London SE5 8AF, UK

\section{References}

Abayneh S, Lempp H, Alem A, Alemayehu D, Eshetu T, Lund C, Semrau M, Thornicroft G, Hanlon C (2017). Service user involvement in mental health system strengthening in a rural African setting: qualitative study. BioMed Central Psychiatry 17, 187.

Chisholm D, Heslin M, Docrat S, Nanda S, Shidhaye R, Upadhaya N, Jordans M, Abdulmalik J, Olayiwola $S$, Gureje O, Kizza D, Mugisha J, Kigozi F, Hanlon C, Adugna M, Sanders R, Pretorius C, Thornicroft G, Lund C (2017). Scaling-up services for psychosis, depression and epilepsy in sub-Saharan Africa and South Asia: development and application of a mental health systems planning tool (OneHealth). Epidemiology and Psychiatric Sciences 26, 234-244.

Gurung D, Upadhyaya N, Magar J, Giri NP, Hanlon C, Jordans MJD (2017). Service user and care giver involvement in mental health system strengthening in Nepal: a qualitative study on barriers and facilitating factors. International Journal of Mental Health Systems 11, 30.

Jordans MJ, Chisholm D, Semrau M, Upadhaya N, Abdulmalik J, Ahuja S, Alem A, Hanlon C, Kigozi F, Mugisha J, Petersen I, Shidhaye R, Lund C, Thornicroft G, Gureje O (2016). Indicators for routine monitoring of effective mental healthcare coverage in low- and middle-income settings: a Delphi study. Health Policy and Planning 31, 1100-1106.

Patel V, Thornicroft G (2009). Packages of care for mental, neurological, and substance use disorders in low- and middle-income countries: PLoS Medicine Series. Public Library of Science Medicine 6, e1000160.

Patel V, Chisholm D, Parikh R, Charlson FJ, Degenhardt L, Dua T, Ferrari AJ, Hyman S, Laxminarayan R, Levin C, Lund C, Medina Mora ME, Petersen I, Scott J, Shidhaye R, Vijayakumar L, Thornicroft G, Whiteford H, Group DMA (2016). Addressing the burden of mental, neurological, and substance use disorders: key messages from Disease Control Priorities, 3rd edition. Lancet 387, 1672-1685.

Petersen I, Evans-Lacko S, Semrau M, Barry MM, Chisholm D, Gronholm P, Egbe CO, Thornicroft G (2016).

Promotion, prevention and protection: interventions at the population- and community-levels for mental, neurological and substance use disorders in low- and middle-income countries. International Journal of Mental Health Systems 10, 30.

Petersen I, Marais D, Abdulmalik J, Ahuja S, Alem A, Chisholm D, Egbe C, Gureje O, Hanlon C, Lund C, Shidhaye R, Jordans M, Kigozi F, Mugisha J, Upadhaya N, Thornicroft G (2017). Strengthening mental health system governance in six low- and middle-income countries in Africa and South Asia: challenges, needs and potential strategies. Health Policy and Planning 32, 699-709.

Samudre S, Shidhaye R, Ahuja S, Nanda S, Khan A, Evans-Lacko S, Hanlon C (2016). Service user involvement for mental health system strengthening in India: a qualitative study. BioMed Central Psychiatry 16, 269.

Semrau M, Evans-Lacko S, Alem A, Ayuso-Mateos JL, Chisholm D, Gureje O, Hanlon C, Jordans M, Kigozi F, Lempp H, Lund C, Petersen I, Shidhaye R, Thornicroft G (2015). Strengthening mental health systems in low- and middle-income countries: the Emerald programme. BioMed Central Medicine 13, 79.

Thornicroft G, Tansella M (2005). Growing recognition of the importance of service user involvement in mental health service planning and evaluation. Epidemiologia e Psichiatria Sociale 14, 1-3.

Thornicroft G, Cooper S, Bortel T V, Kakuma R, Lund C (2012). Capacity building in global mental health research. Harvard Review of Psychiatry 20, 13-24.

Thornicroft G, Chatterji S, Evans-Lacko S, Gruber M, Sampson N, Aguilar-Gaxiola S, Al-Hamzawi A, Alonso J, Andrade L, Borges G, Bruffaerts R, Bunting B, de Almeida JMC, Florescu S, de Girolamo G, Gureje O, Haro JM, He Y, Hinkov H, Karam E, Kawakami N, Lee S, Navarro-Mateu F, Piazza M, Posada-Villa J, de Galvis YT, Kessler RC (2017). Undertreatment of people with major depressive disorder in 21 countries. British Journal of Psychiatry 210, 119-124.

Upadhaya N, Jordans MJ, Abdulmalik J, Ahuja S, Alem A, Hanlon C, Kigozi F, Kizza D, Lund C, Semrau M, Shidhaye R, Thornicroft G, Komproe IH, Gureje O (2016). Information systems for mental health in six low and middle income countries: cross country situation analysis. International Journal of Mental Health Systems 10, 60.

Wang PS, Aguilar-Gaxiola S, Alonso J, Angermeyer MC, Borges G, Bromet EJ, Bruffaerts R, de Girolamo G, de Graaf R, Gureje O, Haro JM, Karam EG, Kessler RC, Kovess V, Lane MC, Lee S, Levinson D, Ono $Y$, Petukhova M, Posada-Villa J, Seedat S, Wells JE (2007). Use of mental health services for anxiety, mood, and substance disorders in 17 countries in the WHO world mental health surveys. The Lancet 370, 841-850.

World Health Organization (2001). Mental health: new understanding, new hope. In World Health Report. World Health Organization: Geneva.

World Health Organisation (2016). mhGAP Intervention Guide for Mental, Neurological and Substance use Disorders in Non-Specialized Health Settings: Mental Health Gap Action Programme (mhGAP) (Version 2.0). World Health Organization: Geneva. 